\title{
Pomegranate moth is the most dangerous pest of pomegranate bushes in the conditions of the Western part of Azerbaijan
}

\author{
F.A. Guliyev ${ }^{1}$ and L.A. Huseynova ${ }^{2 *}$ \\ 1Lankaran Regional Scientific Center of ANAS, Lankaran, Azerbaijan \\ ${ }^{2}$ Scientific Research Institute for Plant Protection and Industrial Crops, Ganja, \\ Azerbaijan \\ Corresponding author email: fitopatoloq.Lale@mail.ru
}

\begin{abstract}
The pomegranate moth (Euzophera punicacella Mocre.) is the most widespread and well-known pest of pomegranate bushes in the western part of Azerbaijan. The loss of yield from the pomegranate moth (Euzophera punicacella Mocre.) in the pomegranate orchards of Azerbaijan often reaches significant sizes. The article provides data on the biology, prevalence, harmfulness of the pomegranate moth (Euzophera punicacella Mocre.), as well as measures to combat it. Research work was carried out from 2018 to 2020 in the pomegranate orchards of the Ganja-Kazakh geographic zone: route surveys, stationary observations, laboratory field and field experiments. Stationary observations were carried out in the industrial pomegranate orchards of the Goranboy region (western part of Azerbaijan, part of the GanjaKazakh geographic zone). Caterpillars collected from damaged fruits in a pomegranate garden served as the material for the study. To determine the harmfulness of the pomegranate moth (Euzophera punicacella Mocre.), 10 test bushes were isolated on the cultivars 'Krmyzy kabukh' and 'Pink gulosha' before flowering. The harmfulness was established by a systematic analysis of damaged fruits and removable crops from experimental bushes. The wintering place of caterpillars was determined by examining 10 experimental bushes at the age of 7 years. Starting from the third ten-day period of March, we examined weekly carrion, crusts, mummified pomegranate fruits that remain in the garden after harvesting and the bark of boles. When studying the timing of the development of individual phases, the number of generations and other issues in laboratory-field conditions, experiments were set up under gardens mounted on pomegranates. The optimal timing of chemical and biological pest control was recommended based on the study of the biological characteristics of the pomegranate moth (Euzophera punicacella Mocre.).
\end{abstract}

Key words: caterpillar, pupa, egg, generations, pest wintering, harmfulness

\section{INTRODUCTION}

Pomegranate is a valuable subtropical fruit crop, which looks like a tree or a bush, with leaves falling for the winter and a rather long dormant period. Pomegranate is one of the most ancient cultures cultivated by man (Osmolovsky and Bondarenko, 1980; Guliyev and Huseynova, 2020). The genus Punica L. belongs to an ancient plant type, characteristic of the Tertiary period. Fossils of this kind are known from the oligocene and pliocene in Azerbaijan. The birthplace of the cultural pomegranate is Azerbaijan, where the main formative process of this kind took place and from where it spread to other regions of the world: to the east of Asia, including China, and the west to North Africa and Spain. The pomegranate belongs to the pomegranate family (Punicaceae Horan.), which has only one genus, Punica L., which includes two species: the common pomegranate (Punica granatum L.) and the Socotran pomegranate (Punica protopunica Balf.). In subtropical fruit growing, the pomegranate culture has a 
thousand-year history. Distributed across all continents. In Uzbekistan and Tajikistan, mainly with soil cover to protect the plants for the winter frost. On the territory of the former Soviet Union, the largest thickets of wild-growing pomegranate are located in the Eastern Transcaucasia (Azerbaijan). Clumps of wild-growing pomegranate are found in the Tugai forests of Azerbaijan. Currently, there are more than 500 cultivars of pomegranate in the world. Local (aboriginal) cultivars of pomegranate are mainly grown in Azerbaijan. There is a fairly large assortment of local cultivars of pomegranates in Azerbaijan: 'Azerbaijani Gulosha', 'Pink Gulosha', 'Agdam Gulosha', 'Nyuvadinskaya Gulosha', 'Shelley Melesi', 'Shah nar', 'Shirin nar', 'Nazik kabukh', 'Krmyzy kabukh', 'Bala Mursal', 'Kara Bala Mursal', 'Apsheron', 'Azerbaijan', 'Shirvan', 'Veles', 'VIR №1', 'Iridane', 'Farash', 'Nasimi', 'Meikhosh', 'Al-Shirin', 'Ag shirin nar', 'Karabakh nary', 'Agdam shirin nary', 'Meskheti', 'Agdam krmyzy nary', 'Kara nar', etc. (Guliyev and Huseynova, 2020). As already noted, common pomegranate in natural growing conditions is a small tree or large bush up to 3-5 $\mathrm{m}$ in height, with a curved trunk and a highly branched crown. The pomegranate bush has opposite shoots. (Figure 1). Shoots are smooth, straight, thin, ending in apical buds or thorns. Thorn-like endings are more often formed in shoots of short and thickened ones. Lateral buds are small, elongated, up to 2-3 $\mathrm{mm}$ long. The leaves are simple, lanceolate, entire, slightly corrugated, wedge-shaped at the base, rounded at the apex. The leaf blade is dark green, $2-8 \mathrm{~cm}$ long, $1-2 \mathrm{~cm}$ wide. The petiole is short, 0.5-0.7 cm (Figure 2).

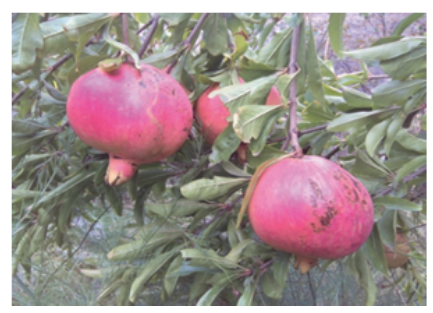

Figure 1. Pomegranate bush ('Pink gulosha' $c v$ )

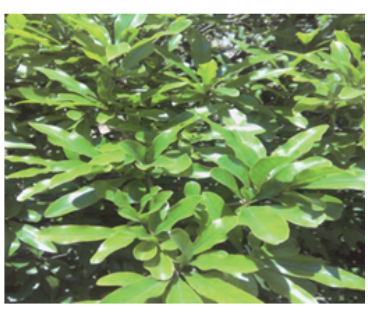

Figure 2. Pomegranate leaves

Pomegranate flowers are dimorphic. Flowers of regular shape, separate-petalled, single, or collected in 3-4 flowers together (less common). One pistil, often underdeveloped, many stamens (Figure 3). Pomegranate fruits are berries with thick skin, large, colored pink, bright red or dark purple, depending on the cultivar. The pomegranate fruit consists of three parts: the peel, seeds and juice (Figure 4). The average weight of fruits is 200-450 gr. The peel with partitions is $35-50 \%$, the seeds are $5-12 \%$, the juice is $40-55 \%$. Pomegranate vegetation begins at an average daily temperature of $10-12^{\circ} \mathrm{C}$ and stops at the same temperature in the fall. Mass budding occurs when the temperature reaches $16-18^{\circ} \mathrm{C}$, the term for fruit development is 120-160 days, depending on the cultivar and weather conditions. The required sum of active temperatures is more than $3000^{\circ} \mathrm{C}$ (Batiashvili, 1965; Guliyev and Huseynova, 2020). Pomegranate (Punica L.) is grown as a fruit, technical, ornamental and medicinal plant. Its fruits are used fresh and used for processing. Pomegranate juice is a valuable food product and is rich in various chemicals. The juice of ripe pomegranate fruits contains $12-19 \%$ sugar, $0.3-3.0 \%$ acid. Sugars are found in the form of glucose, fructose and partly sucrose. Pomegranate juice also contains a large amount of biologically active substances: ascorbic (5 - $12 \mathrm{mg} \%)$, folic $(0.04-0.08 \mathrm{mg} \%)$, P-catechin and leukoanthocyanic (26-46 mg\%) acids, vitamins P (150-200 mg \%), B 1 (0.004-0.036), $\mathrm{B}_{2}$ (0.32-0.27 $\mathrm{mg} \%)$, tannins $(1.0-1.1 \%)$ and pectin's (0.1-0.3\%). Pomegranate growing is one of the leading branches of agriculture in Azerbaijan. With the intensification of pomegranate growing and pomegranate production, the role and importance of plant protection from pests, diseases and weeds as one of the most essential elements ensuring high and sustainable yields from pomegranate bushes increases. 


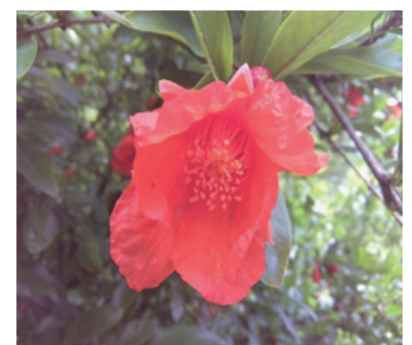

Figure 3. Pomegranate flower

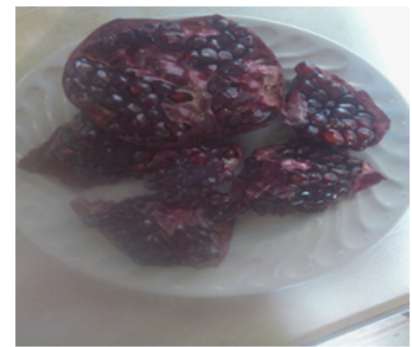

Figure 4. Inside the contents of the fruit

The species composition of pests that damages pomegranate bushes is quite large and varied. Pomegranate bushes damage various polyphagous and specialized pests.

As already noted, pomegranate bushes are attacked by a fairly large complex of various pests. The pomegranate moth (Euzophera punicacella Mocre.) belongs to the class of insects (Insecta), the order butterflies (Lepidoptera), the family of leaf rollers (Tortricidae). The species was first described in 1848 by the german entomologist Philip Christoph Zeller. This pest is widespread in all regions of pomegranate cultivation (Southern Europe, the Caucasus, the Middle East, Iran, North Africa, Asia Minor and Central Asia), and in Azerbaijan (Goranboy, Samukh, Shamkir, Kazakh, Agdam, Terter, Gegchay, Gekgel, especially on Absheron).

The pomegranate moth (imaqo) butterfly is gray. The forewings are narrow, the hindwings are wide. Eggs (ovum) are light yellow, the surface is rough, size $0.75-1.00 \mathrm{~mm}$. Caterpillars (larva) of the last instar are dirty gray. The head is coffee-black, body length $15 \mathrm{~mm}$. This pest of the 4th-5th age in the phase of caterpillars hibernates under the bark of a tree, on leaves, on dried, trunks under the bark, as well as on the skin of fruits in silky cocoons.

\section{GOALS AND OBJECTIVES OF THE RESEARCH}

The main goal of the work is to study the biology, distribution, development and harmfulness of the pomegranate moth in the conditions of the Ganja-Kazakh geographic zone (western part) of Azerbaijan and develop recommendations for combating it. During the research, the following tasks were solved:

1. Studying the biology, distribution, dynamics of development and harmfulness of the pomegranate moth;

2. Study of the resistance of the main cultivars of pomegranate ('Krmyzy kabukh' and 'Pink gulosha') to the pomegranate moth;

3. Study of the influence of agrotechnical measures on the population density of the pomegranate moth;

4. Development, based on the research results, of effective protective measures (mainly an integrated protection system) in the fight against the pomegranate moth;

5. To assess the economic efficiency of the use of chemical and biological means of protecting the pomegranate garden from the pomegranate moth.

\section{MATERIALS AND METHODS}

This chapter of the article provides materials and methods for the study of the pomegranate moth (Euzophera punicacella Mocre.) in the western part (Ganja-Kazakh geographic zone) of Azerbaijan. As already was stated, experimental research was carried out in 2018-2020 in the pomegranate gardens of the Ganja-Kazakh geographic zone (western part of the country) of Azerbaijan. Stationary observations were carried out in the Goranboy region, and route observations in the Geranboy, Shamkir and Kazakh regions. The variants were repeated three times in the experiment. The total area of the experiment was 0.5 hectares. The layout of pomegranate bushes in a $4 \times 4$ garden. The object of research was the 
pomegranate cultivars 'Pink Gyulosha' and 'Krmyzy kabukh'. Caterpillars collected from damaged fruits in a pomegranate garden served as the material for research. The discovered adult butterflies (imago) were soaked in stain, and the larvae and caterpillars (larva) were reared until the imago was obtained. To establish the prevalence of the pomegranate moth (Euzophera punicacella Mocre.), route and stationary surveys were carried out (route surveys were carried out at intervals of 15 days, and stationary surveys were carried out at intervals of 5 days) in the pomegranate plantations of Goranboy, Shamkir, Kazakh regions (these areas are included in the composition of the Ganja-Kazakh geographic zone, the western part of the Republic of Azerbaijan) in 2-3 sections. The number of bushes to be examined depends on the area of the pomegranate garden: up to 50 hectares - 10 bushes; 50-100 hectares - 20 bushes and 100-200 hectares - 30 bushes.

For monitoring the pomegranate moth (Euzophera punicacella Mocre.), the most commonly used delta-shape traps with sticky liners. Pheromone traps were placed in the crowns of a pomegranate bush at a height of 1.5-2.0 m to identify new foci in the period from the second decade of July to the third decade of September to monitor the dynamics of summer and forecast from April to October.

After placing the traps stationary, every seven days, the butterflies were sampled and the liners were replaced in the same order. The harmfulness was established by a systematic analysis of damaged fruits and removable crops from experimental bushes. The wintering place of caterpillars was determined by examining 10 experimental bushes at the age of 7 years. Starting from the third decade of March, we examined weekly carrion, crusts, mummified pomegranate fruits remaining in the garden after harvesting and the bark of boles. The eggs laid were counted after the death of the females.

On the day of death, the female was dissected under a microscope to determine the potential fertility and the presence of spermatophores. Observations of the development of preimaginal phases (eggs, caterpillars, pupa) were also carried out in field and laboratoryfield conditions. For the control of pomegranate moth (Euzophera punicacella Mocre.), in the experimental variants were used biological: Fitoverm (organic treatment based on Aversectin S, $2 \mathrm{~g} / \mathrm{l}$ ), Lepidocide (biological treatment, the product active agent is bacterial spores and protein crystals (delta-endotoxin) of Bacillus thuringiensis var. kurstaki, BA$3000 \mathrm{EA} / \mathrm{mg}$, titer not less than 60 billion spores/g), and Bicol (biological treatment based to Bacillus thuringiensis var. thuringiensis, BA- $2000 \mathrm{EA} / \mathrm{g}$, titer not less than 45 billion spores/g), but and the chemical treatment using Fas product (chemical insecticide from the group of synthetic pyrethroids, deltamethrin $10 \mathrm{~g} / \mathrm{kg}$ ). The treatments were applied foliar, using mechanical equipment.

For this purpose, part of the caterpillars was left on the bush and systematically continued observation of their development in natural conditions, and the other part was transferred to the laboratory to clarify the lifestyle of phenology, as well as to clarify their infestation with parasites.

To study the duration of development of eggs of the pomegranate moth (Euzophera punicacella Mocre.), the experiments were carried out in 5 variants, three replicates each. Butterflies were included in the experiments on the first day of life. In variant I, butterflies obtained at the beginning of summer were used, in variants II, III, IV, V at a later date. In each replication, there were up to 10 pairs of butterflies, which were released into gauze insulators worn on pomegranate branches. Insulators were put on the fruiting branches of pomegranate bushes. Daily observations revealed the onset of oviposition. When the first eggs were found, the butterfly isolators were removed and the branches were labeled. Thus, systematic observations established the timing of hatching and completion of caterpillar development. We also collected pomegranate moth caterpillars (Euzophera punicacella Mocre.) from each generation. Pupae were also collected in pomegranate fruits after feeding 
cessation and leaving for pupation. The collection was carried out on 100 bushes so that at least 500 specimens could be collected. During the research, generally accepted methods were used: monitoring and signaling treatments (Makhotkin, Pavlyushin, 2002), signaling the timing of chemical or biological control and determining its feasibility, monitoring the phytosanitary state of gardens, determination of the population density and economic damaging threshold number (EDT) of the moth.

\section{RESULTS AND DISCUTIONS}

The pomegranate moth (Euzophera punicacella Mocre.) is a widespread and dangerous pest of pomegranate bushes in the western part of Azerbaijan. Route surveys, stationary observations, laboratory and field experiments established that the development of the pest occurs in 3-4 generations per year. Butterfly years last from mid-May to October. The last generation survives the winter in the larval stage (under the bark, in damaged fruits that remain on trees, and in carrion). According to a study carried out in Azerbaijan, in an individual living in the first half of summer, the egg period lasts 6-8 days, caterpillars 20-25 days, pupae 10-12 days; in an individual living in the second half of summer, the egg stage takes 5-7 days, caterpillars 10-12 days, pupa about a crescent (Figure 5-6). Overwintered individuals spend 17-20 days in the pupal phase.

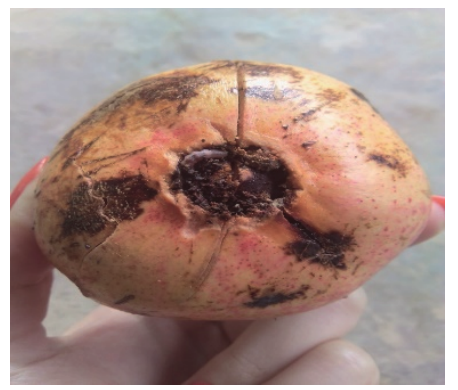

Figure 5. Caterpillar of the fruit moth in the under the influence of pest caterpillars

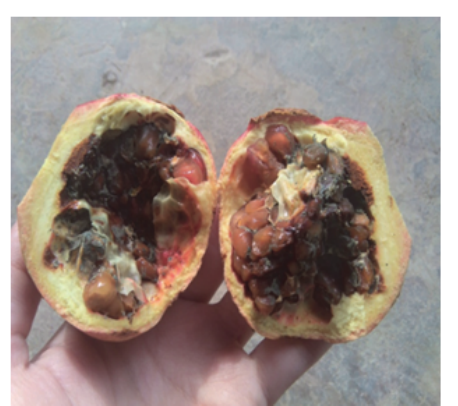

Figure 6. Rotten pomegranate fruit serrated part of the fruit

The phase harmful to the pomegranate is the caterpillar, which penetrates at the earliest stages of development into the fruit of the pomegranate, where they feed on the seeds that have not yet hardened. Our research has found that caterpillars penetrate not only at the earliest stages of development into the pomegranate fruit and feed on not yet hardened seeds, but even on the cups of the ovaries. Thus, caterpillars of the pomegranate moth (Euzophera punicacella Mocre.) gnaw on the phloem in the trunk and feed on the contents of the fruit.

When studying the distribution and harmfulness of the pomegranate moth (Euzophera punicacella Mocre.), we found that some part of the first-generation caterpillars (15-20\%) ends their development in the calyx (Figure 7-8). The results of route surveys and stationary observations showed that the percentage of damage to fallen flowers due to caterpillars of the first generation (pomegranate flowers fall off after laying eggs) varies in the western regions from 1,0 to $2,45 \%$. When even the smallest pomegranate fruits are damaged by the moth, some cultivars of pomegranate damage the fruit up to $50 \%$. Consequently, this contributes to a decrease in yield and a deterioration in quality. The pomegranate moth (Euzophera punicacella Mocre.) inflicts especially great harm on the following pomegranate cultivars: 'Krmyzy kabukh', 'Ag shirin nar', 'Nazik kabukh', 'Azerbaijan' or 'Red gulosha', 'Pink gulosha' and slightly damages the cultivars 'Shirin nar', 'VIR№1'. 
Table. 1. Development phenogram Euzophera punicacella Mocre. on pomegranate in the conditions of the western part (Ganja-Kazakh geographic zone) in 2019-2020

\begin{tabular}{|c|c|c|c|c|c|c|c|c|c|c|c|c|c|c|c|c|c|c|c|c|c|c|}
\hline \multirow{2}{*}{$\begin{array}{l}\text { Generatio } \\
\text { ns }\end{array}$} & \multicolumn{3}{|c|}{ March } & \multicolumn{3}{|c|}{ April } & \multicolumn{3}{|c|}{ May } & \multicolumn{3}{|c|}{ June } & \multicolumn{3}{|c|}{ July } & \multicolumn{3}{|c|}{ August } & \multicolumn{3}{|c|}{ September } & \multirow{2}{*}{$\begin{array}{l}\text { Winter } \\
\text { ing }\end{array}$} \\
\hline & I & II & III & I & II & $\begin{array}{l}\text { II } \\
\text { I }\end{array}$ & I & II & $\begin{array}{l}\text { II } \\
\text { I }\end{array}$ & I & II & $\begin{array}{l}\text { II } \\
\text { I }\end{array}$ & I & II & $\begin{array}{l}\text { II } \\
\text { I }\end{array}$ & I & II & $\begin{array}{l}\text { II } \\
\text { I }\end{array}$ & I & II & III & \\
\hline \multirow{3}{*}{$\begin{array}{l}\text { I } \\
\text { (wintered) } \\
\text { generation }\end{array}$} & $\bullet$ & $\bullet$ & $\bullet$ & $\bullet$ & $\bullet$ & $\bullet$ & $\bullet$ & $\bullet$ & $\bullet$ & $\bullet$ & $\bullet$ & $\bullet$ & $\bullet$ & - & - & - & - & - & - & - & - & \\
\hline & - & - & - & $\Delta$ & $\Delta$ & $\boldsymbol{\Delta}$ & $\boldsymbol{\Delta}$ & $\Delta$ & $\Delta$ & $\boldsymbol{\Delta}$ & $\Delta$ & - & - & - & - & - & - & - & - & - & - & \\
\hline & - & - & - & - & - & - & - & + & + & + & + & + & + & + & + & - & - & - & - & - & - & \\
\hline \multirow{3}{*}{$\begin{array}{l}\text { II } \\
\text { generation }\end{array}$} & - & - & - & - & - & - & - & $x$ & $x$ & $x$ & $x$ & $x$ & $x$ & $x$ & $x$ & - & - & - & - & - & - & \\
\hline & - & - & - & - & - & - & - & - & $\bullet$ & $\bullet$ & $\bullet$ & $\bullet$ & $\bullet$ & $\bullet$ & $\bullet$ & $\bullet$ & - & - & - & - & - & \\
\hline & - & - & - & - & - & - & - & - & - & - & + & + & + & + & + & + & + & + & - & - & - & \\
\hline \multirow{3}{*}{$\begin{array}{l}\text { III } \\
\text { generation }\end{array}$} & - & - & - & - & - & - & - & - & - & - & $x$ & $x$ & $x$ & $x$ & $x$ & $x$ & $x$ & $x$ & $x$ & - & - & \\
\hline & - & - & - & - & - & - & - & - & - & - & - & $\bullet$ & $\bullet$ & $\bullet$ & $\bullet$ & $\bullet$ & $\bullet$ & $\bullet$ & $\bullet$ & $\bullet$ & - & $\bullet$ \\
\hline & - & - & - & - & - & - & - & - & - & - & - & - & - & - & - & - & - & - & - & - & - & \\
\hline
\end{tabular}

Note: $\bullet$-caterpillars; $\mathbf{\Delta}$ pupae; +-butterflies; $x$-egg; -not found

The emergence of the first butterflies (imaqo) of this generation begins on June 22. From the available material, we can say that this phase is extremely extended. Since the pupation of the second-generation caterpillars is uncommon. The flyout of the butterflies (imaqo) is also stretched. 2-3 days after emergence, butterflies (imaqo) begin to lay eggs (ovum). Eggs (ovum) are laid in the cup of the pomegranate fruit. Embryonic development of the third generation lasts 5-7 days. Hatching caterpillars (larva) penetrate the pomegranate fruit through the calyx and feed on the juicy pulp of the grains, their kernels, placentas, as well as fruit crusts, pollute the passages with excrements, bring in the spores of phytopathogenic fungi, causing the fruit to rot. One caterpillar damage one fetus during its life. In one fruit, we found from 1 to 4 caterpillars of the pomegranate moth. As a rule, caterpillars (larva) hibernate, ready to pupate. Caterpillars (larva) of younger ages also remain for wintering. According to our collections, a large percentage of them overwinter safely. To develop effective methods of combating the pomegranate moth (Euzophera punicacella Mocre.) pomegranate, we researched three directions: establishing the effectiveness of agrotechnical, hygienic measures and developing chemical control measures. To this end, field experiments were laid in the pomegranate garden of the Goranboy region (western part of Azerbaijan), where the following agrotechnical measures were tested: pruning dry, diseased, old branches, harvesting leaves and mummified fruits, cultivating the soil around the bush and applying mineral fertilizers - superphosphate, cleaning of affected areas, disinfection and coating with a $1 \%$ solution of copper sulfate. The measures were carried out in early spring before bud break, the effectiveness of each measure was tested separately, against the pomegranate moth (Euzophera punicacella Mocre). One of the criteria for determining the need for chemical treatment is the economic threshold of harmfulness (EPV) (usually 2\%) and the sum of effective temperatures (the threshold for establishing an average daily temperature of $+10^{\circ} \mathrm{C}$ ).

Chemical preparations are used only in case of massive damage by the moth. When spraying a pomegranate from a moth, you can find out with the help of a pheromone trap, which must be located in the garden area. If more than five butterflies fall into it within a week, it means that chemical treatment of the bushes can no longer be done.

In addition to agrotechnical measures against the pomegranate moth (Euzophera punicacella Mocre.), we paid particular attention to the development of a chemical and biological methods of control- integrated pest control. To this end, the following insecticides were tested: Lepidotsid, Bicol, Fitoverm, Fas. (Table 2). 

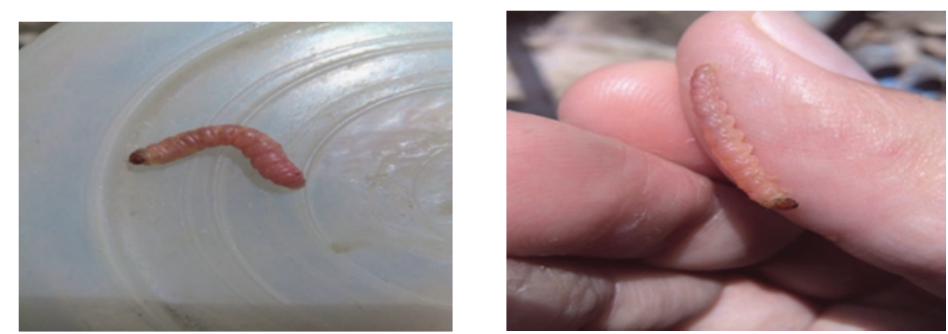

Figure 7-8. Caterpillars identified from pomegranate fruits

Table 2. Influence of preparations on damage to pomegranate fruits of cultivars 'Kyrmyzy kabukh' and 'Pink gyulosha' (2020)

\begin{tabular}{|c|c|c|c|c|c|}
\hline \multirow{2}{*}{ Cultivar } & \multicolumn{5}{|c|}{ Biological efficacy, \% } \\
\cline { 2 - 6 } & Fitoverm & Lepidocide & Fas & Bicol & $\begin{array}{c}\text { Control (without chemical or } \\
\text { biological treatment) }\end{array}$ \\
\hline 'Krmyzy kabukh' & 91 & 78 & 77 & 73 & 0 \\
\hline 'Pink gulosha' & 98 & 77 & 74 & 71 & 0 \\
\hline
\end{tabular}

As a result of observations, the greatest biological effectiveness was shown by Fitoverm, ke, which was 91 and $98 \%$ on the 15th day on the cultivars 'Krmyzy Kabukh' and 'Pink Gulosha', respectively. Of all the drugs used, Bicol turned out to be less effective $71-73 \%$, respectively, for the same cultivars. In connection with the prospects of Fitoverm in the fight against the pomegranate moth (Euzophera punicacella Mocre.), in 2020 we assessed the use of the drug at different consumption rates in different phenophases of pomegranate in industrial gardens. The results are shown in Table 3. So, the biological preparation Fitoverm can be effectively used in gardens when it is included in the general scheme of protective measures, taking into account preliminary monitoring in the conditions of the western part of Azerbaijan. When using the proposed system, there were no residual amounts of insecticides in the removable products, which makes it possible to recommend it as economically safe.

When the average daily air temperature reaches from $5^{\circ} \mathrm{C}$ to $10-12^{\circ} \mathrm{C}$, the time comes for the first spraying of pomegranate bushes with pesticides. Effective pomegranate pest control depends mainly on the timely and correct application of chemicals and biological. For early spring (before bud break) and late autumn (after leaf fall) spraying of pomegranate orchards, we used insectofungicide and insectoacaricide 'Clean Garden Nitro'.

Table 3. Biological efficacy of Fitoverma ('Krmyzy kabukh'), \% of fruit damage (2020)

\begin{tabular}{|c|c|c|c|c|c|c|c|c|}
\hline \multirow[b]{2}{*}{$\begin{array}{l}\text { Phenophase } \\
\text { of } \\
\text { pomegranate }\end{array}$} & \multicolumn{4}{|c|}{ Fitoverm (1 l / ha) } & \multicolumn{4}{|c|}{ Fitoverm (2 l / ha) } \\
\hline & 5 days & 7 days & 10 days & 14 days & 5 days & 7 days & 10 days & 14 days \\
\hline Fruit growth & 75.4 & 79.8 & 84.5 & 85.1 & 77.8 & 80.6 & 82.1 & 88.3 \\
\hline Fruit ripening & 78.9 & 83.2 & 84.5 & 89.7 & 74.7 & 83.5 & 85.6 & 89.7 \\
\hline
\end{tabular}

The drug was used in the late autumn period (after the leaves fell to 70-80\%) and in the early spring period before bud break, to prevent, and protecting against various diseases and insect pests on pomegranate bushes. The drug effectively fights against mosses and lichens, captures a wide range of fungal and infectious diseases, while not harming the culture itself and the environment. 
The processing of pomegranate bushes against the pomegranate moth is carried out at the beginning and after the end of mass flowering, as well as in the third decade of June - the first decade of July.

\section{CONCLUSIONS}

Our 3-year observations in the pomegranate orchards of the western part of Azerbaijan showed that the pomegranate moth (Euzophera punicacella Mocre.) develops mainly in three generations. In the conditions of the Goranboy region, the first pupae appeared in nature in 2019 - April 23, when the average daily air temperature reached $14.3^{\circ} \mathrm{C}$. Mass transformation of caterpillars in pupae was observed in mid-May at a sum of effective temperatures of $180-192^{\circ} \mathrm{C}$, an average of $186^{\circ} \mathrm{C}$.

Butterflies fly at night, during the day they sit in shaded places, on bushes or the grass. Butterflies live for 3 to 9 days, with an average of 6 days. Oviposition by females of the overwintered generation begins 2-3 days after emergence at a sum of effective temperatures of $124.2-138.0^{\circ} \mathrm{C}$. Females lay eggs in buds, flowers and ovaries. Particularly intensive emergence of butterflies of the overwintered generation in the western part of the country occurs after flowering, on the 7-10th day.

The biological preparation Fitoverm protects the pomegranate from the pomegranate moth (biological efficiency 78-89\%; damage to fruits during harvesting $0.7-2.1 \%$; the value of the saved yield 0.6-0.8 $\mathrm{t} / \mathrm{ha}$ ) when using a dosage of $2 \mathrm{l} / \mathrm{ha}(0.2 \%$ working solution).

Other used preparations (Lepidocid, Fas, Bicol) in industrial pomegranate orchards also provide high efficiency (respectively, Lepidocide 77-78\%; Fas 74-77\%; Bicol 71-73\%), while damage to the removable crop ranges from 0.6 up to $2.7 \%$ (with a threshold of the harmfulness of 2-5\%, for cultivars 'Krmyzy Kabukh' and 'Pink Gyulosha' of different fruit weights), and the value of the preserved yield is from 0.6 to $1.4 \mathrm{t} / \mathrm{ha}$.

The monitoring system, adapted for the conditions of the western part of Azerbaijan, allows regulating the population density of the pomegranate moth (Euzophera punicacella Mocre.), maintaining its population at an economically imperceptible level.

\section{REFERENCES}

1. Osmolovsky G.E., and Bondarenko N.V. (1980). Entomology. Leningrad Branch 'Kolos', (1980);122 p.

2. Batiashvili I.D. and Dekanoidze G.I. (1974). Entomology. (In Georgian). Tbilisi, (1974); 38 p.

3. Batiashvili I. D. (1965). Pests of continental and subtropical fruit crops. Tbilisi; 85 p.

4. Guliev F.A., and Huseynova L.A. (2020). Diseases of rotting pomegranate and methods of dealing with them / Proceedings of the Azerbaijan Geographical Society, journal 'Geography and natural resources', №2 (12): 86-91 p.

5 Guliev F.A., and Huseynova L.A. (2020). The role of resistant varieties in the fight against the main diseases of pomegranate in the Ganja-Gazakh geographical region/ 'News of the Azerbaijan State Economic University' journal, №4: 5-16 p.

6. Guliev F.A., and Huseynova L.A. (2020). The species composition of causative agents of pomegranate diseases in the Ganja-Kazakh geographic zone and the improvement of measures to combat the main ones/ Perm Agrarian Bulletin №3 (31): 39-51 p.

7. Guliev F.A., and Huseynova L.A. (2020). Phytopathological examination of pomegranate orchards in the western part of Azerbaijan / Materials of the VII International scientific-practical conference 'Science and Education in the modern world: Challenges of the XXI century', Kazakhstan, 60-68 p. 5.

8. Guliev F.A., and Huseynova L.A. (2020). Parasitic fungi of pomegranate bushes in the western part of Azerbaijan / Scientific collection of the Institute of Viticulture and Winemaking, issue 57, Odessa

9. Huseynova L.A. (2018). The main diseases of pomegranate plants and measures to combat them/ Bulletin of the Ganja branch of ANAS, №3 :p, 118-122.

10. Huseynova L.A. (2020). Fungicides to protect pomegranate from a complex of phytopathogens / International scientific and practical journal 'Global Science and Innovation 2020: Central Asia', Kazakhstan, 31-35 p. 